\title{
Development of a stress-based approach for achieving the risk assessment of fault-related coal and gas outburst
}

\section{Qinglong Zhou*, Juan Herrera-Herbert and Arturo Hidalgo}

\author{
Departamento de Ingeniería Geológica y Minera, \\ ETS de Ingenieros de Minas y Energía, \\ Universidad Politécnica de Madrid (UPM), \\ C/Alenza 4, 28003 Madrid, Spain \\ Email: q.zhou@alumnos.upm.es \\ Email: juan.herrera@upm.es \\ Email: arturo.hidalgo@upm.es \\ *Corresponding author
}

\begin{abstract}
In underground mining, gas accumulation or gas content anomaly caused by geological structures often results in catastrophic coal and gas outburst accidents, this kind of outburst has already been reported for decades and caused thousands of casualties. However, so far there have been very few studies about how to conduct risk assessment for this kind of geological-structure-related outburst. In this study, our aim is to develop an approach to evaluate the risk of fault-related outburst. The approach developed in this study is a stress-based approach and it considers the associated factors including the gas pressure, the fault attitude and the tectonic stresses. The fault-related outburst index proposed in this work not only can be used for evaluating the fault sealing capability but also can be used for quantitatively assessing the risk degree of fault-related outburst. It is a practical approach and can be recommended to apply in more underground engineering. [Received: February 11, 2017; Accepted: August 17, 2017]
\end{abstract}

Keywords: gas outburst; fault sealing; fault plane; seal capability; mine disaster.

Reference to this paper should be made as follows: Zhou, Q., Herrera-Herbert, J. and Hidalgo, A. (xxxx) 'Development of a stress-based approach for achieving the risk assessment of fault-related coal and gas outburst', Int. J. Oil, Gas and Coal Technology, Vol. X, No. Y, pp.xxx-xxx.

Biographical notes: Qinglong Zhou is currently a $\mathrm{PhD}$ student in the Department of Geological and Mining Engineering at the Universidad Politecnica de Madrid, Spain. He received his BS and MS from the Liaoning Technical University and Taiyuan University of Technology in China in 2010 and in 2013 respectively. His current research interests mainly focus on the risk assessment and safety management of underground mining activities.

Juan Herrera-Herbert is a Professor of Mining Technology in the Department of Geological and Mining Engineering at Universidad Politecnica de Madrid. He received his PhD degree in 1995 and since 2000 he has been working on the teaching and the research of mining technology, mine design, mine project evaluation and drill technology. 
Arturo Hidalgo is a Professor of Geological and Mining Engineering at Universidad Politecnica de Madrid with expertise in Applied Mathematics and Numerical Simulation. In recent years, he has conducted a number of researches in solving fluid-related climatological and engineering problems by using the finite volume framework.

\section{Introduction}

Coal and gas outburst, which involves the sudden, violent ejection of a huge volume of coal and gas into the mine workings in a short period of time (Xu et al., 2014), is a typical serious underground hazard occurred in the process of mining or excavating in mining and tunneling engineerings. Since the first documented outburst accident occurred in Issac Colliery, Loire coal field, France, in 1843 (Lama and Bodziony, 1996), to date, over 30,000 outbursts have occurred all over the world in most of the coal-producing countries (Lama and Bodziony, 1998), a detailed historical account of the global incidence of outbursts can be seen in Beamish and Crosdale's (1998) work. Among these coalproducing countries China had the most serious situation and almost one third of the outbursts actually occurred in China, and since 2000 the situation has become more serious because the large-scale coal mining has to be implemented for supporting the rapid development of China's economy. In Table 1, the statistics of the occurred coal and gas outburst accidents in China from 2001 to 2011 are listed.

So far many factors have been proved to contribute in a greater or lesser degree to coal and gas outburst in previous studies, factors such as gas content (Bustin and Clarkson, 1998; Wang et al., 2011), gas pressure (Andreas et al., 2004), coal strength, coal rank (Faiz et al., 1992), hydrological conditions (Scott, 2002), geological structures (Shepherd et al., 1981; Shepherd, 1995; Wold et al., 2008), mining-induced stress (Durucan and Edwards, 1986), mining depth, etc. and among these factors geological structures is definitely a critical one.

As early as 1967, based on a study conducted in west Wales outburst coal mines, Farmer and Pooley (1967) discovered that "geological conditions are an important factor in determining the site of an outburst since outbursts only occur in districts subject to severe tectonic movement - hence their association in many places with anthracite - and in association with such deformation and depositional structures as folds, faults, rolls and slips". More early reports about outbursts and geological structures in coal mines can be seen in Shepherd et al.'s (1981) research, after investigating the outburst occurrences in the UK, Canada, Australia, Poland and France, he found that "mesoscopic and mine-scale geological structures form the loci for stress and gas concentrations, and that probably over $90 \%$ of significant outbursts have been at such sites", in addition, a case study conducted also by Shepherd et al. (1980) in Collinsville, Queensland, Australia even suggested that "thrust and strike-slip faults have been common sites of outbursts, in contrast to normal faults, which were not outburst-prone". In Japan, a huge coal and gas outburst accident occurred at Sunagawa coal mine, $1,600 \mathrm{~m}^{3}$ coal and $60,000 \mathrm{~m}^{3}$ gas were involved in the accident and outburst site was investigated in detail to clarify the geological features, a normal and a reverse fault existed at the site (Sato and Fujii, 1989). The Donets Basin, a major coal-mining district in eastern Ukraine, is also recognised as a high outburst region with frequent instantaneous outburst accidents, according to 
Sachsenhofer et al.'s (2012) research, the reason for the high frequency of gas accidents in such region was mainly attributed to geological structures because strike-slip faults are recognised across the entire basin. According to a study conducted in Turkey (Fisne and Esen, 2014), coal and gas outbursts in Zonguldak Coal Basin are also influenced by faults, the authors discovered that a big portion of the outburst incidents (77\%) actually occurred at fault zones or areas passing through the fault zones and the probability of the outburst occurrences is decreased to move away from the fault zone.

In China, studies (Cao et al., 2001, 2003) over the past decades have also come to the similar conclusion, which is that the majority of outbursts actually occurred in long, narrow 'outburst zones' along the intensely deformed zones of strike-slip, reverse or normal faults. Among the 102 large state-owned coalfields, Pingdingshan coalfield, Huannan coalfield and Huaibei coalfield are three of them have the most serious situations in coal and gas outbursts. In Pingdingshan coalfield, where the studies (Zhai et al., 2016; Wang et al., 2016) conducted from both Zhai and Wang suggested that geological structure is the dominant factor in influencing the outbursts, a research from Cao et al. (2001) even pointed out that in Pingdingshan coalfield the coal and gas outbursts associated with reverse faults nearly always occurred in the footwalls. In Huainan and Huaibei coalfields, outbursts controlled by geological structures are also revealed from various studies (Wang et al., 2013a, 2013b; Xu et al., 2014; Guo et al., 2014).

Although the geological-structure-related outburst has already been a very serious problem and there have already been so many reports on it (as described in the above paragraphs), there are just very few studies on the risk assessment of such hazard. In a earlier research, Shepherd et al. (1981) believed that fault types may be categorised in order of outburst proneness as strike-slip reverse normal; according to Lama and Bodziony's (1998) view, fault throw and fault gouge can be used to determine the fault-related outburst risk, the similar view also can be seen in Cao et al.'s (2001) work, he discovered that the throw magnitude of a reverse fault is of great importance in assessing its outburst tendency; in recent years, using the damage degree of the technically deformed coal (TDC) as a key indicator (Hou et al., 2012) to evaluate the risk of fault-related outburst has been widely applied in China.

Through carefully summarising all the traditional techniques given in the last paragraph, regardless of the fault type method, the fault throw method or the TDC method, actually they all use a common feature, which was named in Beamish and Crosdale's (1998) research as coal seam disruption, to evaluate the fault-related outburst risk. However, the seam disruption is just a superficial phenomenon, the most basic factor is the stress conditions, it is the stress conditions that directly affect the degree of the seam disruption. If we want to develop a more basic method to achieve the risk assessment of fault-related outbursts, the stress analysis is very necessary. Therefore, in this study, our research goal is to develop a more basic stress-based approach to evaluate the risk of fault-related outbursts.

The paper is organised as follows, in the following section, two typical examples of fault-related outburst accidents in China will be given to show what the exact fault-related outburst is. In Section 3, the detailed analysing algorithms of the normal and shear stresses of the fault plane will be given. In Section 4, a quantitative assessment index will be developed to achieve the risk assessment of the fault-related outburst. In 
Section 5, a case study will be conducted by using our developed quantitative assessment approach. In the last section, some conclusions will be given.

Table 1 The statistic of the coal and gas outburst accidents in China from 2001 to 2011

\begin{tabular}{lcc}
\hline Year & Number of outburst accidents & Total deaths \\
\hline 2001 & 41 & 190 \\
2002 & 44 & 347 \\
2003 & 68 & 265 \\
2004 & 41 & 388 \\
2005 & 44 & 180 \\
2006 & 40 & 252 \\
2007 & 35 & 248 \\
2008 & 33 & 256 \\
2009 & 19 & 232 \\
2010 & 29 & 237 \\
2011 & 22 & 183 \\
\hline
\end{tabular}

Source: Li et al. (2013)

\section{Two typical examples of fault-related outburst accidents in China}

\subsection{Panyi coal mine, Anhui Province, China}

Located in Huainan city, Anhui province, Panyi coal mine is a state-owned large-scale coal mine with annual output of 5.0 Mt coal and more than 10,000 employees.

For years, Panyi coal mine has been threatened by frequent gas outburst disasters (Nan and Feng, 2004), the average relative gas emission rate in this mine is as high as $12.55 \mathrm{~m}^{3} / \mathrm{t}$. In Figure 1, the most serious geological-structure-related outburst area is shown. The hangingwall of the normal fault $F_{e 8}$ and the hangingwall of the reverse fault $F_{5}$ are two of the zones have the most frequent outburst incidents, to date, 24 times of recorded outburst incidents have occurred in these two zones. One of the most serious outburst accidents occurred in 2000, which was induced by a blasting and 226 tons of coal and $3,908 \mathrm{~m}^{3}$ of gas were involved in the accident, resulting in the death of 5 miners.

\subsection{Tianfu coal mine, Sichuan Province, China}

Located in the Baoding fold-Huayingshan reverse fault belt (Figure 2), Tianfu coal mine is another mine has the problem of fault-related outbursts. The Huayingshan reverse fault, extending several hundred kilometers, has a throw of 1,500 $\mathrm{m}$ and has developed a drag syncline in its footwall. Due to the shallow depth of the coal seam, adit mining method was applied in this mine. According to a report (2001) recorded by Cao, three large outburst incidents occurred near the reverse faults $\left(F_{8}\right.$ and $\left.F_{4}\right)$ at 300 to $600 \mathrm{~m}$ depth. The first (no. 1 in Figure 2) is the largest outburst ever recorded in China, except the outburst of the largest volume of gas, up to 12,780 tons of coal and rock involved in this outburst event; no. 2 ejected 2,807 tons of coal and no. 3 ejected more than 5,000 tons of coal, and both were accompanied by large volumes of gas. 
Figure 1 Geological structures and the distribution of outburst points in Panyi coal mine (see online version for colours)

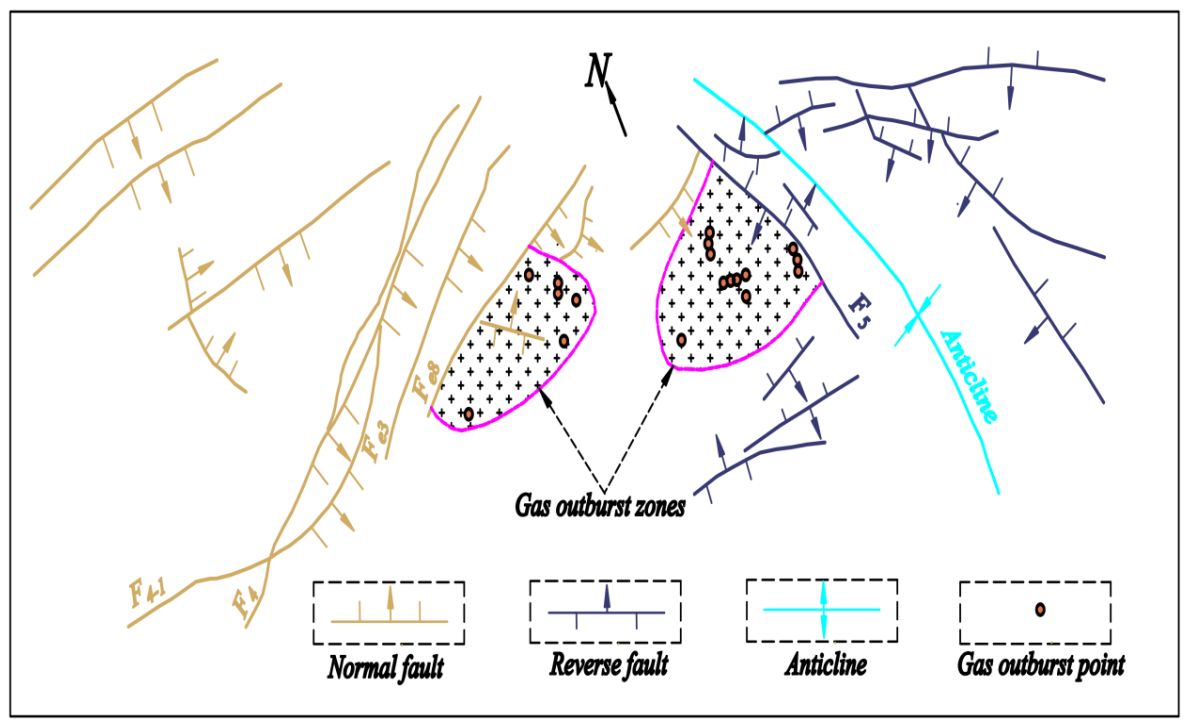

Source: After Nan and Feng (2004)

Figure 2 Outburst locations (in circles) in the geologic cross-section of Tianfu coal mine (see online version for colours)

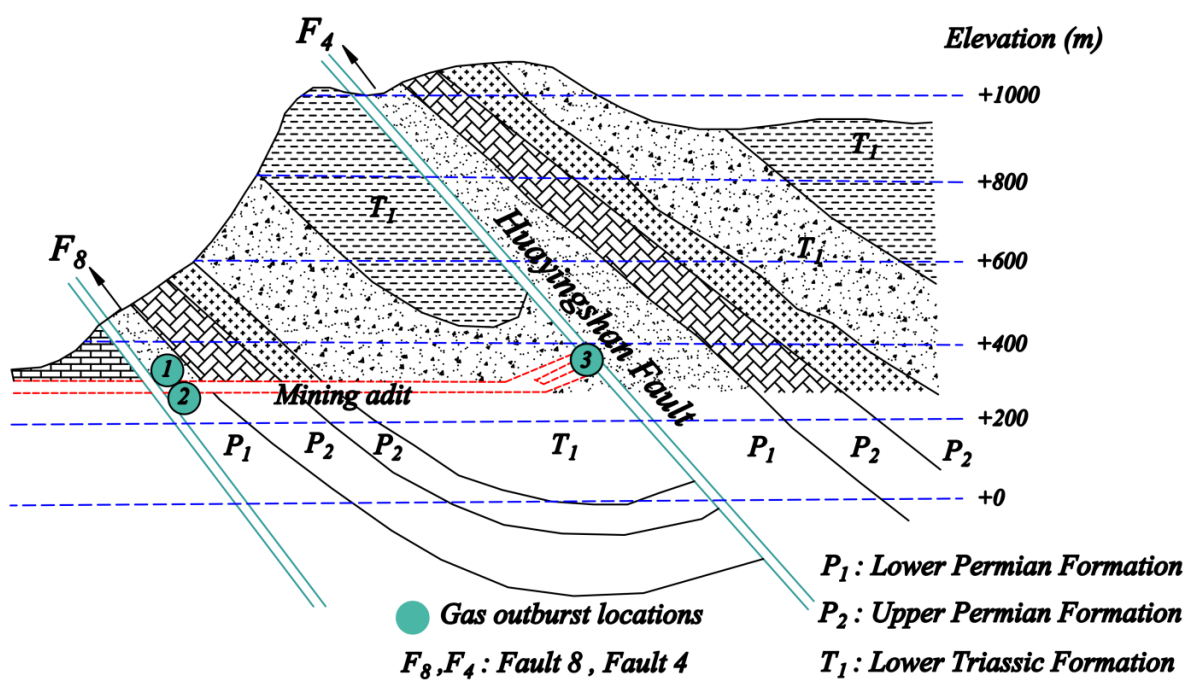

Source: After Cao et al. (2001) 


\section{The analysis of the normal and the shear stresses of the fault plane}

\subsection{Establishing a mathematical model for fault plane}

Anderson (1951) postulated a fundamental relation between the three basic fault modes (Figure 3) and the orientation of the causative stress tensor relative to the Earth's surface. According to his view, the Earth's surface is free boundary (no shear or normal traction), therefore, one principal axis of crustal stress tensors will commonly be vertical and the other two axes will be horizontal (Robert, 1997).

Figure 3 The orientation of the causative stresses of the three basic fault modes (see online version for colours)
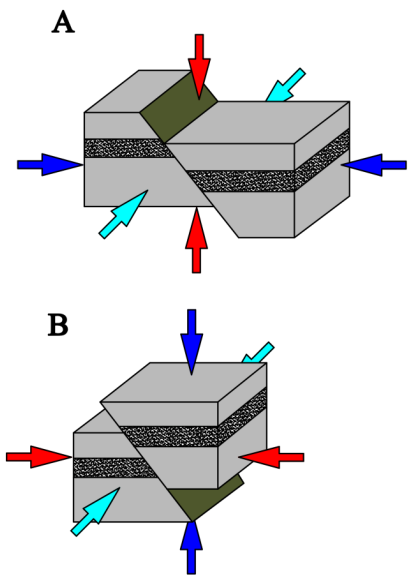

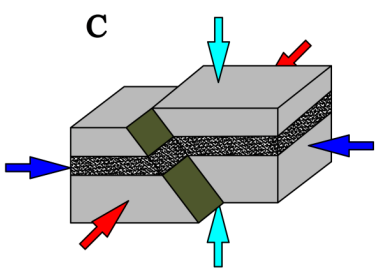
A: Normal fault
B: Reverse fault
C: Strike-slip fault

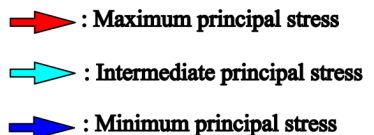

Figure 4 Using a 3D Cartesian coordinate system to express the fault plane (see online version for colours)

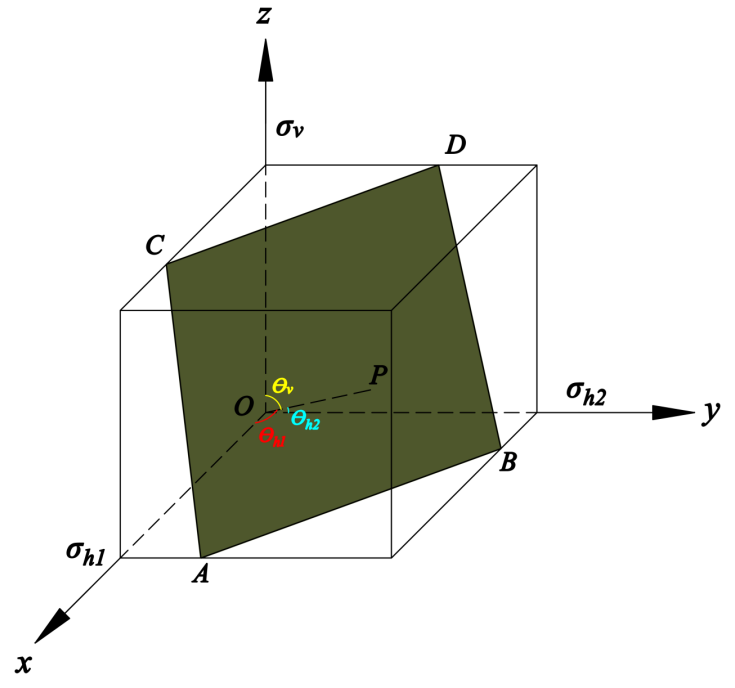


In order to facilitate the stress analysis, a 3D Cartesian coordinate system (Figure 4) is established based on the fault plane extracted from Figure 3, in this coordinate system, the $\mathrm{x}$-axis and $\mathrm{y}$-axis represent two of the horizontal stresses $\left(\sigma_{h 1}\right.$ and $\left.\sigma_{h 2}\right)$ respectively and the vertical stress $\sigma_{v}$ is represented by z-axis. Assuming $O P$ is the perpendicular line to the fault plane, $\theta_{h 1}$ is the angle between $O P$ and $\sigma_{h 1}, \theta_{h 2}$ is the angle between $O P$ and $\sigma_{h 2}$ and $\theta_{v}$ is the angle between $O P$ and $\sigma_{v}$.

What needs to be emphasised here is that in this study how the variation of thickness and lithology of the fault zone influence the stress of the fault plane will not be considered.

\subsection{Normal and shear stresses of the fault plane determine fault sealing capability}

For most of the fault-related outbursts, local gas accumulation near the fault zone caused by fault sealing is the most important factor. To assess the risk of a fault-related outburst, it is necessary to assess the fault sealing capability. In previous studies (Yielding et al., 1997; Fulljames et al., 1997; Ciftci et al., 2013; Pei et al., 2015), scientists have considered that the permeability of the fault zone is closely related to fault rocks as they believed the structures of pores and fractures are only determined by rock types. However, in this study, we only partially agree with their point of view, we believe that the stresses of the fault plane rather than rock types is the most important factor to determine the structures of pores and fractures, and this is also to say that the stresses of the fault plane has the most impact on the fault sealing capability and has the most important impact on local gas accumulation, our arguments are as follows:

1 If the normal stress of the fault plane is tensile stress, fractures and pores in the fault zone will be opened to facilitate gas transport, in this case the fault is open and it will not cause local gas accumulation or local gas content anomaly. On the contrary, if the normal stress of the fault plane is compressive stress, the closure of the fractures and pores will lead to fault sealing and then cause gas accumulation or gas content anomaly.

2 How the shear stress of the fault plane affects the fault sealing capability depends on whether there is a mutual movement between the footwall and the hangingwall. If the shear stress is greater than the shear strength of the fault rock, a mutual movement between the footwall and the hangingwall will occur, and such movement will make the closure of part of the pores and fractures in the fault zone, thus decreasing the permeability of fault rocks and then increasing the fault sealing capability. On the contrary, if the shear stress is less than the shear strength of the fault rocks, only static friction exists between the footwall and the hangingwall, the fault sealing capability will not be affected.

\subsection{Stress analysis of the fault plane}

According to the trigonometric and geometrical relations established in Figure 4, the normal and shear stresses ( $\sigma$ and $\tau$ ) of the fault plane can be obtained by using the principles of stress decomposition and superposition as follow:

$$
\sigma=\sigma_{h 1} \cos ^{2} \theta_{h 1}+\sigma_{h 2} \cos ^{2} \theta_{h 2}+\sigma_{v} \cos ^{2} \theta_{v}
$$




$$
\tau^{2}=\sigma_{h 1}^{2} \cos ^{2} \theta_{h 1}+\sigma_{h 2}^{2} \cos ^{2} \theta_{h 2}+\sigma_{v}^{2} \cos ^{2} \theta_{v}-\sigma^{2}
$$

As the vertical principal stress is mainly determined by the depth $H$ and the unit weight $\gamma$, hence we have:

$$
\sigma_{v}=\gamma H
$$

The horizontal stresses are mainly composed of two parts, the horizontal tectonic stresses $\left(\sigma_{x}\right.$ and $\left.\sigma_{y}\right)$ and the component $\left(\sigma_{v}^{c}\right)$ of the vertical principal stress. They are expressed as follows:

$$
\begin{aligned}
& \sigma_{h 1}=\sigma_{v}^{c}+\sigma_{x} \\
& \sigma_{h 2}=\sigma_{v}^{c}+\sigma_{y}
\end{aligned}
$$

$\sigma_{v}^{c}$ is not only relevant to the vertical principal stress but also relevant to the lateral pressure coefficient:

$$
\sigma_{v}^{c}=\sigma_{v} \xi
$$

where $\xi$ is the lateral pressure coefficient tied with the Poisson's ratio $(\mu): \xi=\mu /(1-\mu)$. With equation (1) and equation (2)- equation (6), the normal and the shear stresses of the fault plane can be comprehensively expressed as:

$$
\begin{aligned}
& \sigma=\left(\gamma H \xi+\sigma_{x}\right) \cos ^{2} \theta_{h 1}+\left(\gamma H \xi+\sigma_{y}\right) \cos ^{2} \theta_{h 2}+\gamma H \cos ^{2} \theta_{v} \\
& \tau^{2}=\left(\gamma H \xi+\sigma_{x}\right)^{2} \cos ^{2} \theta_{h 1}+\left(\gamma H \xi+\sigma_{y}\right)^{2} \cos ^{2} \theta_{h 2}+(\gamma H)^{2} \cos ^{2} \theta_{v}-\sigma^{2}
\end{aligned}
$$

\section{Quantitative assessment of the risk of the fault-related outburst}

In general, strike and dip usually are used for representing the orientation or attitude of a geologic feature, and in engineering practices the spatial position of the fault plane is usually represented by a strike and a dip angle rather than by angles $\left(\theta_{h 1}, \theta_{h 2}, \theta_{v}\right)$ that we used hereinabove, so here we need to convert $\theta_{h 1}, \theta_{h 2}$ and $\theta_{v}$ to the strike angle and the dip angle.

By further developing the geometric relationships from Figure 4 to Figure 5, assuming $\alpha$ and $\beta$ are the strike angle and the dip angle respectively and the length of OE is 1 , the following trigonometric relations then can be derived:

$$
\begin{aligned}
& \cos \theta_{h 1}=\sin \alpha \sin \beta \\
& \cos \theta_{h 2}=\cos \alpha \sin \beta \\
& \cos \theta_{v}=\cos \beta
\end{aligned}
$$


Figure 5 Geometric relationships between the angles $\left(\theta_{h 1}, \theta_{h 2}, \theta_{v}\right)$ and the strike, dip angles (see online version for colours)

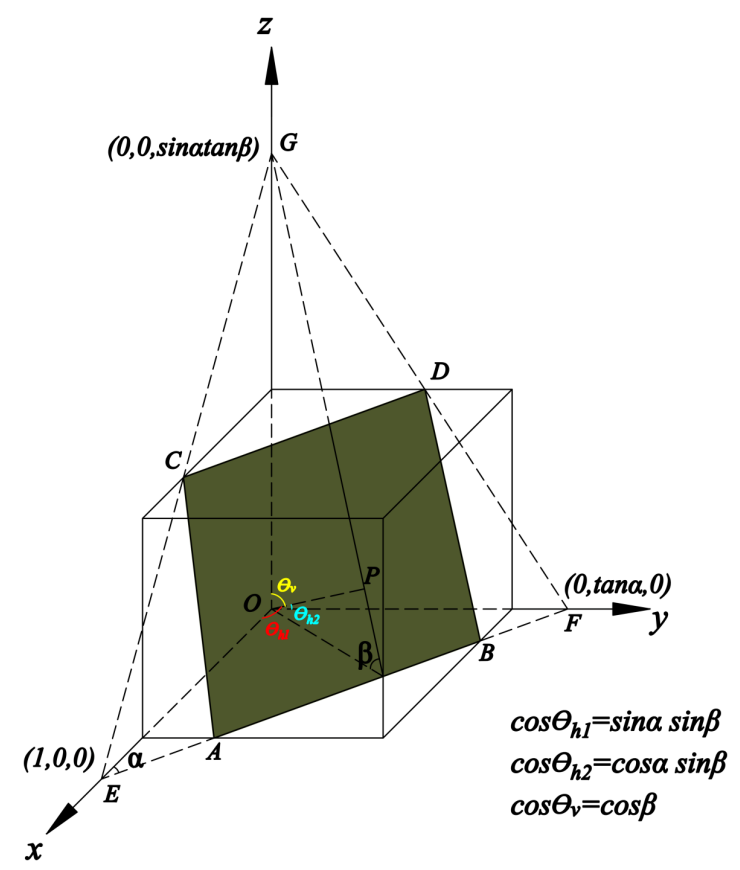

Substituting equation (9)-equation (11) into equation (7) and equation (8), the final representations of the normal and the shear stresses of the fault plane then can be obtained as:

$$
\begin{aligned}
& \sigma=\left(\gamma H \xi+\sigma_{x}\right) \sin ^{2} \alpha \sin ^{2} \beta+\left(\gamma H \xi+\sigma_{y}\right) \cos ^{2} \alpha \sin ^{2} \beta+\gamma H^{2} \cos ^{2} \beta \\
& \tau^{2}=\left(\gamma H \xi+\sigma_{x}\right)^{2} \sin ^{2} \alpha \sin ^{2} \beta+\left(\gamma H \xi+\sigma_{y}\right)^{2} \cos ^{2} \alpha \sin ^{2} \beta+(\gamma H)^{2} \cos ^{2} \beta-\sigma^{2}
\end{aligned}
$$

In the last section, we discussed that the fault sealing capability depends on the stresses of the fault plane, so here two indexes $(I, Q)$ are further defined to represent the fault sealing capability by using the normal and shear stresses of the fault plane.

$$
\begin{aligned}
& I=\frac{\sigma}{P} \\
& Q=\left|\frac{\tau}{\tau_{c}}\right|
\end{aligned}
$$

where $P$ denotes the gas pressure; $\tau_{c}$ denotes the shear strength of fault rock. These two indexes are very useful for the risk assessment of fault-related outburst:

$I<0$ means the normal stress of the fault plane is tensile stress and the fault is in a state of opening, the fault will not affect the gas transport through the fault zone, and there will be a low risk of outburst near fault zone. 
$0 \leq I \leq 1$ represents that the normal stress of the fault plane is compressive stress and the fault is in a state of sealing, but the sealing capability is limited, high gas pressure still allows the gas to transport through the fault zone.

$I>1$ indicates the normal stress of the fault plane is compressive stress and the fault is in a state of sealing, the larger the value, the better the sealing capability, and the risk of outburst near fault zone will be increase with the increase of the index.

$Q>1$ means that the shear stress of the fault plane is greater than the strength of the fault rocks, and there will be a mutual movement between the footwall and the hangingwall and the fault sealing capability will be increased.

$Q \leq 1$ indicates that only static friction exist between the footwall and the hangingwall, the fault sealing capability will not be affected.

In underground engineering, a fault that is capable of causing huge gas accumulation is generally a large fault (Creedy, 1988; Li, 2001). For such a fault, even in the case of mining disturbances or blasting disturbances, the mutual displacement between the footwall and the hangingwall caused by the shear stress is negligible, in this sense it means that actually index $Q$ has a quiet small influence in fault sealing. Therefore, the fault sealing actually mainly depends on the normal stress of the fault plane and this means index I can be completely used for representing the fault sealing capability. As fault-related outburst is directly relevant to fault sealing capability, so index I also can be used for representing the risk of fault-related outburst (in this sense, we define index I as the outburst index).

Next, we will continue to discuss how the outburst index $(I)$ is affected by the associated parameters. By using the double-angle and half-angle formulas into equation (12), together with equation (14) the outburst index $(I)$ can be further derived as:

$$
I=\frac{1}{2 P}\left\{\gamma H(1+\cos 2 \beta)+\left(\gamma H \xi+\frac{\sigma_{x}+\sigma_{y}}{2}-\frac{\sigma_{x}-\sigma_{y}}{2} \cos 2 \alpha\right)(1-\cos 2 \beta)\right\}
$$

As can be seen from equation (16), all the associated parameters including the depth $H$, the strike angle $\alpha$, the dip angle $\beta$ and the tectonic stresses $\left(\sigma_{x}\right.$ and $\left.\sigma_{y}\right)$ directly affect the outburst index. In Figure 6, how the depth impacts on the outburst index is given, the outburst index increase with the increase of depth. How the dip angle affects the fault sealing can be seen in Figure 6 and Figure 7, the result is not simple as the outburst index will increase with the increase of dip angle, it depends on the scales of the vertical principal stress (related to $H$ ) and the difference between the two tectonic stresses $\left(\sigma_{x}-\sigma_{y}\right)$; as shown in Figure 6, the outburst index decreases with the increase of the dip angle when the depth is small and increases when the depth is large. The similar situation also can be seen in Figure 7, how the dip angle impacts on the outburst index is determined by the difference between the two horizontal tectonic stresses $\left(\sigma_{x}-\sigma_{y}\right)$, the outburst index will rise with the increase of dip angle when the tectonic stress difference is large and will decrease when the difference is small. In Figure 8, how the strike angle and the tectonic stress difference affect the outburst index is displayed, the larger the tectonic stress difference the higher the outburst index is and the outburst index increase with the increase of the strike angle. 
Figure 6 The impact of the burial depth on the outburst index (see online version for colours)

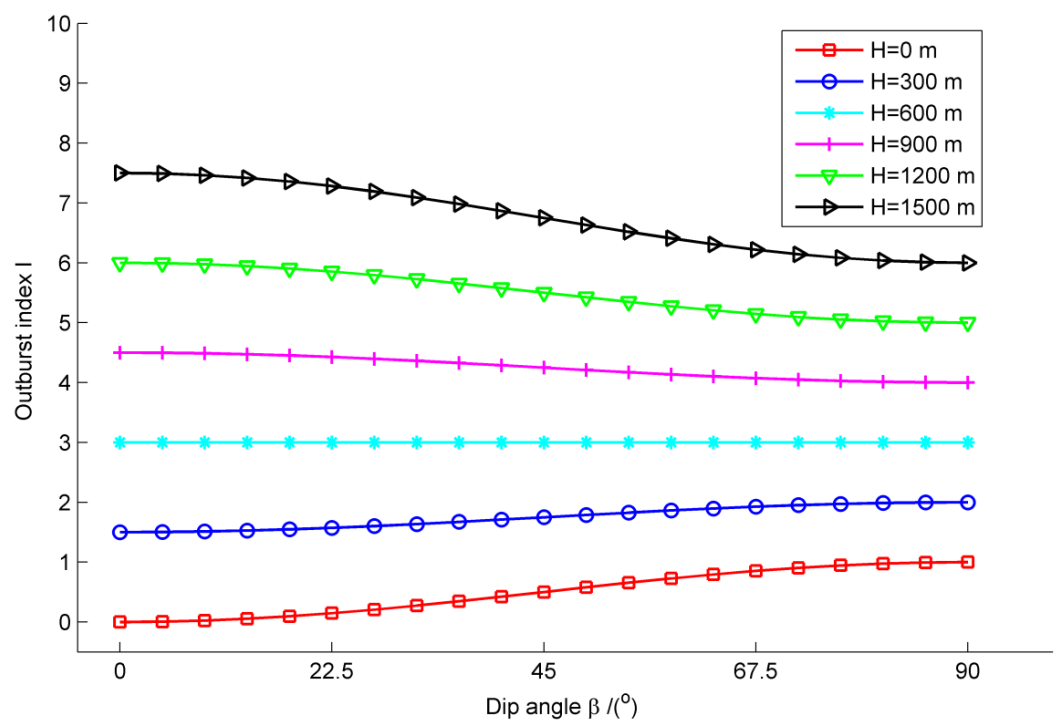

Figure 7 The impact of dip angle on the outburst index (see online version for colours)

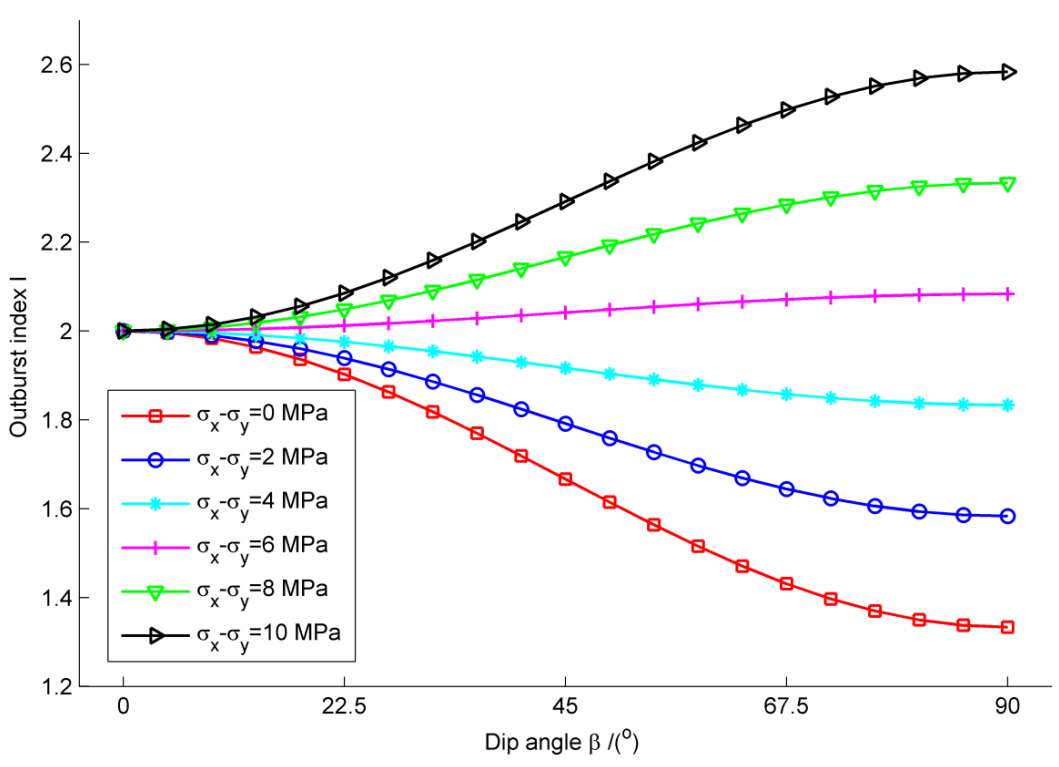


Figure 8 The impact of strike angle on the outburst index (see online version for colours)

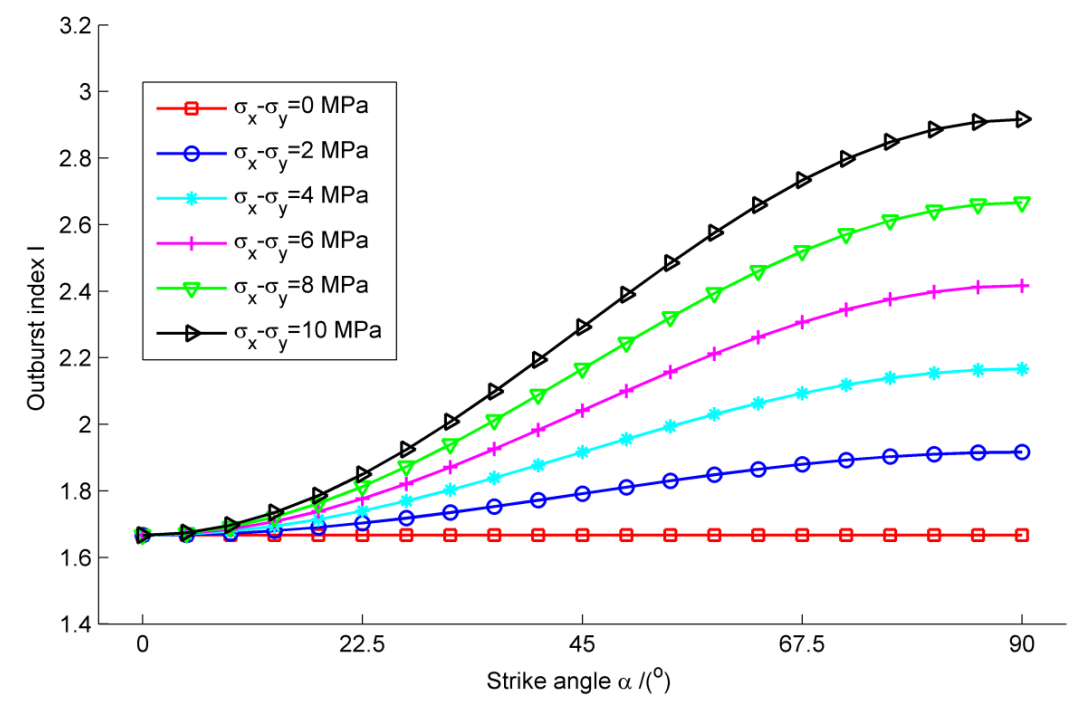

Figure 9 The geological section of the reverse fault in Daping coal mine and the outburst location in roadway no. 21 (see online version for colours)

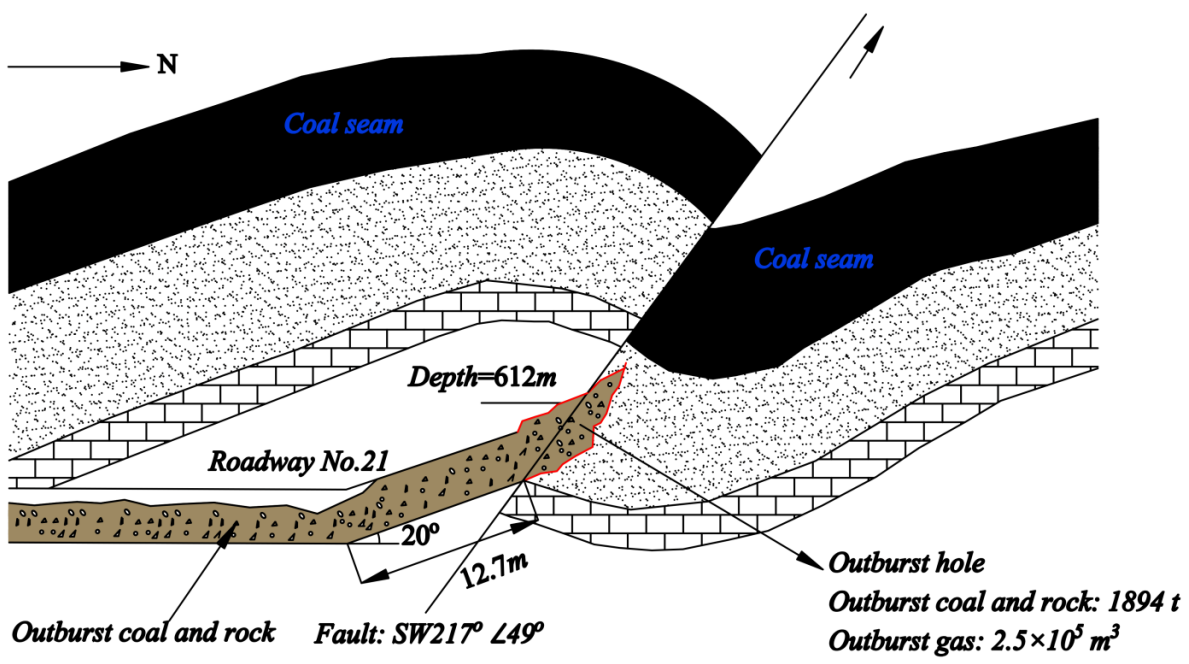

\section{A case study}

Daping coal mine, located in Dengfeng City, Henan Province of China, was initially constructed in 1986 with an annual output of 0.6 million tons of coal. In order to improve the mine production capacity from 0.6 million tons to 1.3 million tons, since 2000 a number of projects on the reconstruction of producing systems began to operate. On 
December 20, 2004, a serious coal and gas outburst accident was occurred in the process of the excavation of a new roadway (roadway No. 21), after the coal and gas outburst (at 22:09), the gas concentration increased rapidly since all the outburst gas rushed into the roadways and a gas explosion eventually was triggered by the electric spark at 22:40. A total of 148 miners were killed and 32 injured in this accident.

It was a typical fault-related outburst accident. In Figure 9, we roughly depict the geological structure of the accident. In the process of the excavation of the roadway No.21, the heading face suddenly encountered a reverse fault $(\mathrm{S} 217 \mathrm{~W}$, fault throw $=$ $10 \mathrm{~m}$ ) at the depth of $612 \mathrm{~m}$, resulting in large volumes of accumulated gas was released in a short period of time. As can be seen from Figure 9, the outburst hole, which is located in the mid-upper position of the heading face, is situated just right on the fault zone.

According to Hou's work (Hou et al., 2012), the outburst area of this accident lies in a structural belt with a concentration of horizontal tectonic stresses, the measured values of the horizontal tectonic stresses $\left(\sigma_{x}\right.$ and $\sigma_{y}$ ) are 5.3 Mpa and $3.4 \mathrm{Mpa}$, respectively. According to the accident report issued by the State Administration of Coal Mine Safety the gas pressure $P=2 \mathrm{MPa}$, the mining depth $H=612 \mathrm{~m}$, the strike angle $a=37^{\circ}$ and the dip angle $\beta=49^{\circ}$, by using all the above described data and equation (16) we then obtain the outburst index $I=6.69$.

Table 2 A comparison between the developed method and the previous proposed methods used in fault-related coal and gas outburst prediction

\begin{tabular}{|c|c|c|}
\hline Methods & Content and parameter & Prediction results \\
\hline \multirow[t]{2}{*}{ Our method } & $\begin{array}{l}I<1 \text { : low risk in fault-related gas } \\
\text { outburst }\end{array}$ & $\begin{array}{l}I=6.69, \text { the fault has a high risk } \\
\text { of fault-related outburst. }\end{array}$ \\
\hline & $\begin{array}{l}I \geq 1 \text { : high risk in fault-related gas } \\
\text { outburst }\end{array}$ & \\
\hline \multirow{2}{*}{$\begin{array}{l}\text { Lama's method } \\
\text { (Lama and } \\
\text { Bodziony, 1998; } \\
\text { Cao et al., 2001) }\end{array}$} & \multirow{2}{*}{$\begin{array}{l}\text { A fault has a throw greater than the } \\
\text { coal seam thickness can result in } \\
\text { complete stoppage of gas flow and } \\
\text { hence more dangerous in outbursts. } \\
\text { Faults without any gouge are less } \\
\text { dangerous, the greater the thickness } \\
\text { of the gouge, the greater is the } \\
\text { danger of outburst. }\end{array}$} & $\begin{array}{l}\text { Fault throw }(10 \mathrm{~m})>\text { coal seam } \\
\text { thickness }(6.3 \mathrm{~m}) \text {; the thickness of } \\
\text { the fault gouge is } 10-15 \mathrm{~cm} \text {. }\end{array}$ \\
\hline & & $\begin{array}{l}\text { According to Lama's method, all } \\
\text { the above two conditions indicate } \\
\text { that the fault has a high risk of } \\
\text { fault-related outburst. }\end{array}$ \\
\hline $\begin{array}{l}\text { TDC method (Hou } \\
\text { et al., 2012) }\end{array}$ & $\begin{array}{l}\text { The damage degree of the TDC } \\
\text { (tectonically deformed coal) is a } \\
\text { key indicator for coal and gas } \\
\text { outburst. The greater the } \\
\text { development of TDC, the greater } \\
\text { the risk in coal and gas outburst. }\end{array}$ & $\begin{array}{l}\text { According to a previous } \\
\text { investigation conducted by Hou } \\
\text { (2012), due to the tectonic effects, } \\
\text { in the juncture of the fault the } \\
\text { TDC was developed in layer, } \\
\text { powdered and deformed intensely. } \\
\text { So the fault has a high risk of } \\
\text { fault-related outburst. }\end{array}$ \\
\hline
\end{tabular}

As can be seen from the results that the outburst index $I$ is far greater than 1 , this indicates the reverse fault encountered in roadway no. 21 has a very good sealing capability and has a very high risk in inducing outburst accidents. In order to verify our prediction result, in Table 2, a comparison between our developed method and the other previous proposed methods (Lama and Bodziony, 1998; Cao et al., 2001; Hou et al., 
2012) is carried out. As can be seen from the table, the prediction result of our method is consistent with the predictions of the other two methods.

\section{Conclusions}

In this study, we developed a stress-based algorithm to assess the fault sealing capability. An outburst index was proposed for quantitatively achieving the risk assessment of the fault-related outburst, the larger the outburst index, the higher the risk of the fault-related outburst. According to the developed algorithm in this study, how the gas pressure, the dip angle, the strike angle and the tectonic stresses impact on the outburst index were obtained, they are as follows:

1 The outburst index increases with the increase of the vertical principal stress.

2 The greater the difference of the two tectonic stresses, the higher the outburst index.

3 How the dip angle impacts on the outburst index depends on the scales of the vertical principal stress and the difference of the two horizontal tectonic stresses.

4 The outburst index increase with the increase of the strike angle.

In addition, although the approach developed in this work provides a new way of assessing the risk of fault-related outburst, what we still want to emphasise here is that instantaneous outbursts in underground is a complicated dynamic phenomenon induced by many factors. So we suggest that in the assessment of outburst risk, we should make a comprehensive assessment by considering all the relevant factors (coal rank, coal strength, hydrological conditions, mining methods, coal adsorption, mining-induced stresses, etc.) rather than just using our approach developed in this study.

\section{References}

Anderson, E.M. (1951) The Dynamics of Faulting and Dyke Formation with Application to Britain, 2nd ed., Oliver and Boyd, Edinburgh.

Andreas, B., Yves, G., Bernhard, M.K. and Ralf, L. (2004) 'Methane and carbon dioxide adsorption-diffusion experiments on coal: upscaling and modeling', International Journal of Coal Geology, Vol. 60, No. 2, pp.151-168.

Beamish, B.B. and Crosdale, P.J. (1998) 'Instantaneous outbursts in underground coal mines: an overview and association with coal type', Int. J. Coal Geol., Vol. 35, No. 1, pp.27-55.

Bustin, R.M. and Clarkson, C.R. (1998) 'Geological controls on coalbed methane reservoir capacity and gas content', Int. J. Coal Geol., Vol. 38, No. 1, pp.3-26.

Cao, Y., Davis, A., Liu, R., Liu, X. and Zhang, Y. (2003) 'The influence of tectonic deformation on some geochemical properties of coals: a possible indicator of outburst potential', Int. J. Coal Geol., Vol. 53, No. 2, pp.69-79.

Cao, Y., He, D. and Glick, D.C. (2001) 'Coal and gas outbursts in footwalls of reverse faults', Int. J. Coal Geol., Vol. 48, No. 1, pp.47-63.

Ciftci, N.B., Giger, S.B. and Clennell, M.B. (2013) 'Three-dimensional structure of experimentally produced clay smears: implications for fault seal analysis', Am. Assoc. Pet. Geol. Bull., Vol. 97, No. 5, pp.733-757.

Creedy, D.P. (1988) 'Geological controls on the formation and distribution of gas in British coal measure strata', Int. J. Coal Geol., Vol. 10, No. 1, pp.1-31. 
Durucan, S. and Edwards, J.S. (1986) 'The effects of stress and fracturing on permeability of coal', Min. Sci. Technol., Vol. 3, No. 3, pp.205-216.

Faiz, M.M., Aziz, N.I., Hutton, A.C. and Jones, B.G. (1992) 'Porosity and gas sorption capacity of some eastern Australian coals in relation to coal rank and composition', Coalbed Methane Symposium, Townsville, pp.19-21.

Farmer, I.W. and Pooley, F.D. (1967) 'A hypothesis to explain the occurrence of outbursts in coal, based on a study of West Wales outburst coal', Int. J. Rock Mech. Min. Sci., Vol. 4, No. 2, pp.189-193.

Fisne, A. and Esen, O. (2014) 'Coal and gas outburst hazard in Zonguldak Coal Basin of Turkey, and association with geological parameters', Nat. Hazards, Vol. 74, No. 3, pp.1363-1390.

Fulljames, J.R., Zijerveld, L.J.J. and Franssen, R.C.M.W. (1997) 'Fault seal processes: systematic analysis of fault seals over geological and production time scales', in Møller-Pedersen, P. and Koestler, A.G. (Eds.): Norwegian Petroleum Society Special Publications, Vol. 7, pp.51-59.

Guo, P., Cheng, Y., Jin, K. and Liu, Y. (2014) 'The impact of faults on the occurrence of coal bed methane in Renlou coal mine, Huaibei coalfield, China', Journal of Natural Gas Science and Engineering, Vol. 17, No. 2, pp.151-158.

Hou, Q., Li, H., Fan, J., Ju, Y., Wang, T., Li, X. and Wu, Y. (2012) 'Structure and coalbed methane occurrence in tectonically deformed coals', Science China Earth sciences, Vol. 55, No. 11 pp.1755-1763.

Lama, R.D. and Bodziony, J. (1996) Outbursts of Gas, Coal and Rock in Underground Coal Mines, R.D. Lama and Associates, Wollongong, NSW, Australia, 499pp.

Lama, R.D. and Bodziony, J. (1998) 'Management of outburst in underground coal mines', Int. J. Coal Geol., Vol. 35, No. 97, pp.83-115.

Li, B., Wang, K., Wei, J.P., Tian, T. and Li, P. (2013) 'On the basic characteristic features and incidental regularity of coal and gas outbursts in China since from 2001 to 2012', Journal of Safety and Environment, Vol. 3, No. 3, pp.274-278.

Li, H. (2001) 'Major and minor structural features of a bedding shear zone along a coal seam and related gas outburst, Pingdingshan coalfield, northern China', Int. J. Coal Geol., Vol. 47, No. 4, pp.101-113.

Nan, C. and Feng, X. (2004) 'Simplified tectonic stress model and analytical solution for concave-circular-arc fault', Chinese Journal of Rock Mechanics and Engineering, Vol. 23, No. 23, pp.3984-3989.

Pei, Y., Douglas, A.P., Rob, J.K. and Wu, K. (2015) 'A review of fault sealing behaviour and its evaluation in siliciclastic rocks', Earth-Sci. Rev., Vol. 150, pp.121-138.

Robert, W.S. (1997) 'Quantifying Anderson's fault types', J. Geophis. Res., Vol. 108, No. 8, pp.909-919.

Sachsenhofer, R.F., Privalov, V.A. and Panova, E.A. (2012) 'Basin evolution and coal geology of the Donets Basin (Ukraine, Russia): an overview', Int. J. Coal Geol., Vol. 89, No. 1, pp.26-40.

Sato, K. and Fujii, Y. (1989) 'Source mechanism of a large scale gas outburst at Sunagawa coal mine in Japan', Pure Appl. Geophys., Vol. 129, Nos. 3-4, pp.325-343.

Scott, A.R. (2002) 'Hydrogeologic factors affecting gas content distribution in coal beds', Int. J. Coal Geol., Vol. 50, Nos. 1-4. pp.363-387.

Shepherd, J. (1995) 'The structure of fault zones in relation to outburst proneness', Int. Symp. cum Workshop on Managementand Control of High Gas Emission and Outbursts, Wollongong, 20-24 March, pp.85-92.

Shepherd, J., Rixon, L.K. and Creasey, J.W. (1980) 'Analysis and prediction of geological structures associated with outbursts at Collinsville, Queensland', in the Occurrence, Prediction and Control of Outbursts in Coal Mines Symposium, Australian Institute of Mining and Metallurgy, Parkville, Victoria, Australia, pp.159-171. 
Shepherd, J., Rixon, L.K. and Griffiths, L. (1981) 'Outbursts and geological structures in coal mines: a review’, Int. J. Rock Mech. Min. Sci. Geomech. Abstr., Vol. 18, No. 4, pp.267-283.

Wang, G., Cheng, W.M., Xie, J. and Zhou, G. (2011) 'Analysis of the gas content in the coal and gas outburst', Journal of China Coal Society, Vol. 36, No. 3, pp.429-434.

Wang, H., Cheng, Y. and Yuan, L. (2013a) 'Gas outburst disasters and the mining technology of key protective seam in coal seam group in the Huainan coalfield', Nat. Hazards, Vol. 67, No. 2, pp.763-782.

Wang, H., Wang, L., Cheng, Y. and Zhou, H. (2013b) 'Characteristics and dominant controlling factors of gas outburst in Huaibei coalfield and its countermeasures', International Journal of Mining Science and Technology, Vol. 23, No. 4, pp.591-596.

Wang, W., Wang, X. and Yan, J. (2016) 'The main factor controlling the coal and gas outbursts in the Eastern Pingdingshan Mining Area', Geotechnical and Geological Engineering, pp.1-10.

Wold, M.B., Connell, L.D. and Choi, S.K. (2008) 'The role of spatial variability in coal seam parameters on gas outburst behaviour during coal mining', Int. J. Coal Geol., Vol. 1, No. 1, pp.1-14.

Xu, C., Cheng, Y., Ren, T., Wang, L., Kong, S. and Lu, S. (2014) 'Gas ejection accident analysis in bed splitting under igneous sills and the associated control technologies: a case study in the Yangliu Mine, Huaibei Coalfield, China', Nat. Hazards, Vol. 71, No. 1, pp.109-134.

Yielding, G., Freeman, B. and Needham, D.T. (1997) 'Quantitative fault seal prediction', Am. Assoc. Pet. Geol. Bull., Vol. 81, No. 6, pp.897-917.

Zhai, C., Xiang, X., Xu, J. and Wu, S. (2016) 'The characteristics and main influencing factors affecting coal and gas outbursts in Chinese Pingdingshan mining region', Nat. Hazards, Vol. 82, No. 1, pp.507-530. 